\title{
IDENTIFICATION OF SCHOOL DEPENDED FACTORS, WHICH CAN AFFECT STUDENTS' PERFORMANCE ON ASSESSMENTS
}

\author{
Marcin Fojcik ${ }^{1}$, Martyna Fojcik ${ }^{2}$, June Audsdotter Stafsnes ${ }^{3}$, \& Bjarte Pollen ${ }^{1}$ \\ ${ }^{1}$ Department of Electrical Engineering, Western Norwegian University of Applied Sciences (Norway) \\ ${ }^{2}$ Department of Computing, Mathematics and Physics, Western Norwegian University of Applied Sciences \\ (Norway) \\ ${ }^{3}$ Research Librarian, Western Norwegian University of Applied Sciences (Norway)
}

\begin{abstract}
The paper tries to define, name and assess different factors, which can affect evaluations results for students. In Norway, like in all EU countries, students need to collect 30 ECTS. To get ECTS students must pass an examination/evaluation at the end of each subject. The ideas of examining the students are to see to which degree the students have learned (assimilate) knowledge from the course. The examination is also a type of assessment to see if the students can choose and use effective study-strategies, and if they know how to prepare for and perform during an examination. It is an evaluation of learned skills and examination performance, not students' personal qualities.

Both research publication and authors experience show that in many situations, the students do not achieve an examination score proper to their skills. There are many reasons for this. In the paper, the authors will not focus on general reasons like economic condition or gender divergences but only on factors that can depend on university strategy, such as stress management, examinations technique, understanding of the tasks, etc.

The results of surveys conducted in all class show that the students have unsatisfactory knowledge about effective exams-strategies. They often know about theoretical problems but have insufficient experience with practical use of this knowledge. If the students are working with the curriculum (syllabus) on their own, they have hard time to perform under pressure. Often, their well-learned skills fail under a trial, because they are not prepared for the evaluation itself. Performing pressure, anxiety and stress are examples of variables that can affect student's execution or presentation of their well-learned skills. The students need to prepare themselves to an exam not only by reading the curriculum and solving past papers, but also by dealing with stress and pressure, by thinking ahead and mentally preparing themselves for the evaluation. Schools and universities should help students by teaching them different study- and examination strategies, so that students know how they can perform their best under exams.

The authors collected data through qualitative and quantitative methods (surveys, interview, and collecting anonymous data from exams results) to research study- and examination-strategies they use. The data was anonymized and analysed. The results were used to identity what factors affect students' performance most. The paper shows some suggestions how schools and universities can support students to be more prepared and self-conscious for this kind of situations.
\end{abstract}

Keywords: Evaluation, study strategies, examination strategies, students, assessments.

\section{Introduction}

To define education as merely formal education is a gross oversimplification (Michalos, 2017). In today's culture it is expected to learn many kinds of things through many ways and contexts, but the word "education" is merely associated with formal education from government schools and universities. Education today needs to "expand academic quality in all aspects, right from the curriculum to the learning-teaching process to examination and evaluation systems" (Aithal \& Kumar, 2016). The oldest university in the Western world, University of Bologna, was founded in $1088 \mathrm{AD}$ in Italy, and it is the first university in Europe for international mobility through Erasmus+ 2018 (University of Bologna). The times are changing, and higher education institutions need to create a model of education that keeps the curriculum in place with changing environment, technology adoption, changing industry requirement, changing aspiration of students and changing expectations of society (Aithal \& Kumar, 2016). 
Norway is a welfare state, where there are small, and mostly insignificant, differences between society classes, especially in the education system. In Norway an access to education is a human right, and everyone is accepted, yet many does not complete their degree. The authors experience stated that the students learn more during the semester then what they show on final assessments. Students that answers correctly in classes, and writes good assignments, does not reach their potential on final exam.

The purpose of this paper was to identify and analyse factors that can affect students' performance and assessment results. Factors that does not depend on society, economic or gender divergences, but factors that can depend on university strategy, teachers' preparations and the students themselves. That is factors that teachers and universities can influence to help prepare students for academic assessments.

In this paper the authors will present some theorical background and previous research on this topic in section 2. Section 3 will present a methodology used to sample data in this project. In section 4 the results will be presented and commented. Last section, section 5, will discuss and conclude this research.

\section{Theoretical background}

\subsection{ECTS credit system}

The European Credit Transfer and Accumulation System (ECTS) was first introduced as a part of Erasmus programme in 1989, to support student exchange and mobility within Europe (ECTS Users' Guide, 2015). This system become a tool to unite, integrate and compare study programs and courses to same scale of quality. The results were positive and ten years later the European higher education institutions wrote down the Declaration Bologna, a part of Bologna Process, an international agreement and standardisation of ECTS (Havnes \& Prøitz, 2016).

ECTS Users Guide states that the students are awarded with credits after they have showed that "the defined learning outcomes have been achieved at the required level" (ECTS Users' Guide, 2015). Furthermore, the Guide states that the relationship between learning outcomes, learning activities and assessment should be an essential requirement for educational programmes, but the Guide does not give any concrete specifications about how the higher education institutions are to conduct the assessments of learning outcomes, neither does is comment the individual needs of students in the learning process.

A. Souto-Iglesias and Baeza_Romero (2018) discussed that there is no way to validate if the courses with same nominal of credits and similar amount of lessons and study hours, have similar amounts of independent study. Furthermore, the study showed that workload in studies, varies from university to university, and can depend on poorly motivated or steered students, inadequately designed courses, part-time jobs, and other factors.

\subsection{Academic performance}

Academic performance is the final part of learning and studying, and a good academic performance consists of much more than good reading or listening features. A. E. Poropat (2009) claimed that different personality traits definitely influences students' performance on assessments.

In psychology the researches were for years trying to systematize personality traits, and current models consist of five recurrent personality factors. E.C. Tupes and R.E. Christal classified the five factors as "surgency", "agreeableness", "dependability" "emotional stability" and "culture" (Tupes \& Christal, 1992). The current five-factor model of personality are can classify major personality traits into: openness (being creative, sensible, broad-minded, open for new things and ideas), conscientiousness (being persistent, dependable, prepared, structured and having the will to achieve), extraversion (being active, social, centre of attention), agreeableness (being reflected, cooperative, caring, friendly) and emotional stability/instability also called neuroticism (being often in stress, often upset, dramatical, unconfident, anxious and having adjustment issues) (Digman, 1990; Phillips, Abraham, \& Bond, 2003; Poropat, 2009; Zhou, 2015).

Poropat (2009) found in his research that there is a strong relationship between academic performance and three of those personality traits: agreeableness, conscientiousness and openness, and he argues that it is the conscientiousness that has the strongest association with academic performance of all the five factor model dimensions. The effect of openness on academic performance is strongly discussed, but the role of conscientious are commonly acknowledged by the researches (Chamorro-Premuzic \& Furnham, 2003; O'Connor \& Paunonen, 2007; Phillips et al., 2003; Zhou, 2015). The research of Zhou (2015) describes that students with lover levels of self-determination are more influenced by the five factor model, than students highly motivated and self-determined. This means that students' motivation is not only a driving force of learning, but it influences student's performance as well. Chamorro-Premuzic and Furnham (2003) discovered that there is significant negative correlation between neuroticism/emotional stability and extraversion on students' performance. This means that students capable to be emotionally stable and introverted have $15 \%$ greater chance to better perform in academic examination performance (Chamorro-Premuzic \& Furnham, 2003). 


\section{Methods}

To answer the research question proposed in this study, the authors researched different student. Participants in this study were students on STEM courses (science, technology, engineering and mathematics) in different years in a Bachelor program. The data was collected through mixed methods. The quantitative survey and examination results from passed years were statistically analyse in paper (Fojcik, Fojcik, Stafsnes, \& Pollen, 2019). The authors wanted to query and interview students at several stages of their engineering-study in order to see if there were differences in study techniques, and how they reflect towards their own ways of dealing with exams and the exam preparations. This article immerses previously founded factors with qualitative interviews to better understand student's perspective and behaviour.

The authors have done a query, with 66 students, and interviews with 4 first-year students, 3 second-year students and 2 third-year students. Students were first informed about this research project through an online learning platform, Canvas, and then the researches also visited all the classes in order to tell more about the project and to find volunteers.

All the data are voluntarily collected, in which the students said yes to be interviewed and signed a statement of consent to be a part of this project. Each interview was based on a semi-structured guide, that was approved be the Norwegian Centre for Research Data, NSD.

\section{Results}

The results obtained from the query show many factors that influences students learning and evaluation process. There are two most visible elements that influences students: stress and expectations. The greatest problem influencing students before assessments is anxiety and stress, which is mentioned by over $60 \%$ of the students. The other problem is that the students that expect grades above average are more critical to themselves and show consciousness on their choices and responsibility. Meanwhile students that expect a passing grade or an average grade, expect the learning process to be given to them - through a passive attitude.

Both of those problems were immersed during interviews. Dialogue also have showed that students do not have specific preferences/experiences and they mention many different things. Yet, there are some differences between first-year students and more experienced students, there were three common factors: students experience on studying and learning, students' preparation and awareness of the assessments itself, and the model of final examination.

\subsection{Differences in students' experience}

After analysing the interviews of all the students, the authors tend to see that the more experience students get in being students, the more reflective they are about their own ways of studying. Those students explain how several aspects of studying affect themselves and what they do about it. First-year students, without any studying experience, tend to do what others do, without reflecting about how they adapt to the environment. Third-year students, and to some point also second-year students were more likely not to differentiate classes, courses and the level of effort in a subject on their own motivation or personal mood, but creating good study habits and structure learning process. While the first-year students were more likely to skip early-classes if they were not interested in the individual topic, or if they knew that they understood the topic.

Another difference between new students and experienced ones is the afford toward reaching desired grade. First-years students tend to fancy above average, top grades and expressing them achieving their goals. Third-year students tend to have goals related to the exam's difficulty and complexity. They tend to be more reflective about themselves both as students and towards how they adapt to the relation between themselves and the academic institution.

\subsection{Anxiety and stress}

The authors wanted to ask the students about the main factors from the query to get the students point of view, but surprisingly none of the students as talking about real nerves and anxiety towards the exam day. They seem to have confidence in their exam preparation, and in the fact that they have done the best to deal with the exam in the very best way they can. The only nerves or anxiety some of the students gets is about what kind of questions they will be on the assessment, or if they remembered everything from lessons. This kind of nerve disappear when they start solving the exam tasks. What is interesting is that all the students the authors talked to mention their classmates having anxieties that gives them a mental block during the exam. These results are not consistent with the result of the query, even more, these results are not normal distributed. 


\subsection{Form of the final assessment}

Most participants in this project claim to have found a way preparing for an academic assessment that works for them. Some students claim to work best alone, others to work best in small groups with other classmates. Nearly all the students said that they work with practical problem-solving task related to the course and topic. Reading was not an effective way of preparing for the exams because the STEM courses are practical orientated, and the students follow this orientation and mainly practice arithmetic.

$89 \%$ of the students argued that the 4-7 hours written exams are not an effective assessment method for STEM courses. Some said that a whole semester depended on one day, and if you got personal matters that put you out of mental balance, you are not able to give your best anyway. Others claims that a written exam does not represent the society or workplace one got today: today you got colleagues to discuss with, and no one expect you to know basically everything there is to know about every topic within the engineering work. They also say that one could get lucky with what he or she reads: one student could know only a small part of the subject, get lucky in the exam tasks and get a top grade. Another one could prepare and read everything except the given task and fail. It's often about how lucky you are with the topics and how your body and mind are on the day of the exam.

\section{Discussion and conclusion}

The authors goal with this project is to create a system that can help and support students in learning and preparing for an academic assessment. This study is limited for STEM courses in a Bachelor program, that makes it to specific database to generate the findings form this research. That is also the specifics of the education. Every student is different, every subject is different, every assessment and every exam, but this project shows some tendencies that teachers and institutions can take into account preparing next students for their final assessments.

Being a student means much more, that just performing well on academic assessments. It is the time to try new things, gather experience, exchange to different country or culture, and find more about himself, discover our strengths and weaknesses, and grow up. Education is not limited to a Bachelor's degree (Michalos, 2017). The personality traits like achievement striving, self-discipline and activity can influence students examination performance in $30 \%$ of known cases (Chamorro-Premuzic \& Furnham, 2003). Furthermore, the knowledge of the factors that can influence students' performance can compensate for known weaknesses and nurture students strengths (O’Connor \& Paunonen, 2007).

Our research indicates that there is a correlation between the student's study strategies and consciousness on their academic performance. The students' performance on objective academic assessments is influenced by their learning style, while application on that knowledge in real-life situations require additional skills (Lynch, Woelfl, Steele, \& Hanssen, 1998). Student in this research complain that the most used form for examination in Norway is 4-7 hours written assessments, a form that does not reflect the current situation in working life. And that the expectations about the examination are high, but very few teachers actually use lessons to teach about different study techniques or different ways on how to prepare for the final assessments to perform on ones best.

An assessment or examination at the end of the semester is the final, and sometimes only, chance to proof ones knowledge in the subject. Usually there are not many occasions the students can show what they have learned and what they can do with that knowledge. Fojcik et al. (2019) discuses that the level of stress before an assessment should be distributed on a normal distribution model. This means that it is optimal for the students to be in a mediate stress during an evaluation, so that their body and mind can focus to perform their best. One may say that students that are not at all stressed, simply do not care enough to perform well. In the interviews the students did not mention any influence of stress or anxiety, nether the positive one or the negative one. A possible explanation is that the word stress, may associate with anxiety and choking under pressure, which those students did not experience. Another outcome may be that the students did not remember the stress after the exams, when they learned that they passed, those positive feelings could shadow the previous negative ones.

It is important to remember that the learning is a process, and students needs to be constantly reminded of the purpose of what they are learning and motivated to keep on working, as well as thinking conscious about the whole learning and performing process. 


\section{Acknowledgements}

The authors would like to thank all the participants in this study for their time and personal insight to the cause. And the Norwegian Centre for Research Data, NSD, for the ethical guidance and General Data Protection Regulation for Research.

\section{References}

Aithal, P., \& Kumar, P. (2016). Analysis of Choice Based Credit System in Higher Education. International Journal of Engineering Research and Modern Education (IJERME) Volume I, Issue I, 278-284.

Chamorro-Premuzic, T., \& Furnham, A. (2003). Personality traits and academic examination performance. European Journal of Personality, 17(3), 237-250.

Digman, J. M. (1990). Personality structure: Emergence of the five-factor model. Annual review of psychology, 41(1), 417-440.

ECTS Users' Guide. (2015). ECTS Users Guide. In Y. Directorate-General for Education, Sport and Culture (European Commission) (Ed.): Publications Office of the European Union.

Fojcik, M., Fojcik, M. K., Stafsnes, J. A., \& Pollen, B. (2019). Studentar og eksamesnvurderingar: ein indentifikasjonsstudie av kva faktorar som påverkar studentar sine presentasjonar på eksamen. Procedings from MNT-konferansen 2019, 28th-29 March, Troms $\varnothing$.

Havnes, A., \& Prøitz, T. S. (2016). Why use learning outcomes in higher education? Exploring the grounds for academic resistance and reclaiming the value of unexpected learning. Educational Assessment, Evaluation and Accountability, 28(3), 205-223. doi:10.1007/s11092-016-9243-Z

Lynch, T. G., Woelfl, N. N., Steele, D. J., \& Hanssen, C. S. (1998). Learning style influences student examination performance. The American Journal of Surgery, 176(1), 62-66.

Michalos, A. C. (2017). Education, happiness and wellbeing. In Connecting the quality of life theory to health, well-being and education (pp. 277-299): Springer.

O’Connor, M. C., \& Paunonen, S. V. (2007). Big Five personality predictors of post-secondary academic performance. Personality and Individual Differences, 43(5), 971-990.

Phillips, P., Abraham, C., \& Bond, R. (2003). Personality, cognition, and university students' examination performance. European Journal of Personality, 17(6), 435-448.

Poropat, A. E. (2009). A meta-analysis of the five-factor model of personality and academic performance. Psychological bulletin, 135(2), 322.

Souto-Iglesias, A., \& Baeza_Romero, M. T. (2018). A probabilistic approach to student workload: empirical distributions and ECTS. Higher Education, 76(6), 1007-1025.

Tupes, E. C., \& Christal, R. E. (1992). Recurrent personality factors based on trait ratings. Journal of personality, 60(2), 225-251.

University of Bologna. (2019). Our history. Retrieved from https://www.unibo.it/en/university/who-we-are

Zhou, M. (2015). Moderating effect of self-determination in the relationship between Big Five personality and academic performance. Personality and Individual Differences, 86, 385-389. 